\title{
The Impact of the New Haven Promise Program on College Enrollment, Choice, and Persistence
}

Lindsay Daugherty, Gabriella C. Gonzalez

RAND Education

WR-1146

April 2016

RAND working papers are intended to share researchers' latest findings. Although this working paper has been peer reviewed and approved for circulation by RAND Education, the research should be treated as a work in progress. Unless otherwise indicated, working papers can be quoted and cited without permission of the author, provided the source is clearly referred to as a working paper. RAND's publications do not necessarily reflect the opinions of its research clients and sponsors. RAND(i) is a registered trademark. 
For more information on this publication, visit www.rand.org/pubs/working_papers/WR1147.html

Published by the RAND Corporation, Santa Monica, Calif.

C Copyright 2016 RAND Corporation

RAND $^{\star}$ is a registered trademark

\section{Limited Print and Electronic Distribution Rights}

This document and trademark(s) contained herein are protected by law. This representation of RAND intellectual property is provided for noncommercial use only. Unauthorized posting of this publication online is prohibited. Permission is given to duplicate this document for personal use only, as long as it is unaltered and complete. Permission is required from RAND to reproduce, or reuse in another form, any of its research documents for commercial use. For information on reprint and linking permissions, please visit www.rand.org/pubs/permissions.html.

The RAND Corporation is a research organization that develops solutions to public policy challenges to help make communities throughout the world safer and more secure, healthier and more prosperous. RAND is nonprofit, nonpartisan, and committed to the public interest.

RAND's publications do not necessarily reflect the opinions of its research clients and sponsors.

Support RAND

Make a tax-deductible charitable contribution at

www.rand.org/giving/contribute

www.rand.org 


\title{
THE IMPACT OF THE NEW HAVEN PROMISE PROGRAM ON COLLEGE ENROLLMENT, CHOICE, AND PERSISTENCE
}

\author{
Lindsay Daugherty \\ Gabriella Gonzalez
}

\author{
WR-1147-UIER \\ RAND CORPORATION \\ 1776 Main Street \\ Santa Monica, CA 90401
}

\author{
April 2016
}

\begin{abstract}
Founded in 2010, the New Haven Promise program provides up to $\$ 10,000$ annually in scholarships for students who attend New Haven Public Schools and live within New Haven City to help defray the costs of tuition in Connecticut public two year and four year colleges. We estimate the impact of being eligible for the program for the first three high school graduate cohorts using regression discontinuity and difference-indifferences approaches. Our results are mixed. Regression discontinuity estimates indicate a positive impact of the New Haven Promise on public college enrollment and several other outcomes, though estimates vary according to specifications, and difference-in-difference estimates indicate null effects. The analysis was limited by data availability around eligibility and the gradual phase-in of the program that resulted in differing benefits and eligibility requirements for the early cohorts of beneficiaries.
\end{abstract}

RAND working papers are intended to share researchers' latest findings. Although this working paper has been peer reviewed and approved for circulation by RAND Education, the research should be treated as a work in progress. Unless otherwise indicated, working papers can be quoted and cited without permission of the author, provided the source is clearly referred to as a working paper. RAND's publications do not necessarily reflect the opinions of its research clients and sponsors. RAND ${ }^{\circledR}$ is a registered trademark.

This paper follows analysis of New Haven reform efforts published in Gonzalez et al., 2014. We thank Lou Mariano and Catherine Augustine for their valuable comments and suggestions. The paper also benefited greatly from feedback received through a consortium of Promise program researchers funded by the Lumina Foundation and coordinated by the W.E. Upjohn Institute. We appreciate the guidance of Patricia Melton, Executive Director of the New Haven Promise, received throughout the project. We thank New Haven Public Schools for providing data for the project, and we thank The Community Foundation of New Haven and the Lumina Foundation for their generous funding. 


\section{Introduction}

The City of New Haven, New Haven Public Schools (NHPS), and The Community Foundation for Greater New Haven launched the New Haven Promise in 2010. The program covers up to $\$ 10,000$ annually for New Haven residents graduating from NHPS or city charter high schools to attend Connecticut public colleges and universities. The New Haven Promise program is one of the many new place-based scholarship programs (often referred to as "promise programs") that have been introduced in states and cities across the United States in recent decades. These programs aim to improve economic development and enhance human capital within a region by providing support for postsecondary education.

This study examines the impact of the New Haven Promise on postsecondary outcomes, adding to a broad literature on the postsecondary impacts of place-based scholarship programs. The analysis focuses on the first three cohorts of beneficiaries—2011 through 2013 graduates—who were eligible for a portion of the full $\$ 10,000$ in annual scholarship funding. We used district data linked to postsecondary data from the National Student Clearinghouse (NSC). We use two different analytic methods to identify the causal impact of eligibility for the Promise program by comparing the outcomes of students who are eligible for the program to those that are ineligible using both regression discontinuity and difference-in-differences.

The study findings are mixed, and we conclude that in the early years of the Promise program, there is not clear evidence that the New Haven Promise led to positive impacts for these initial cohorts of graduates. Our regression discontinuity estimates indicate that eligibility for the New Haven Promise led to increased enrollment in public colleges and potentially on some other enrollment outcomes. However, these

results are sensitive to model specifications. In addition, we do not find any positive impacts of eligibility for the program in our difference-in-difference analysis. We note concerns about our ability to measure the true impact of the New Haven Promise due to data limitations that prevent us from precisely determining eligibility status. In addition, a graduated roll-in of benefits for the initial cohorts may limit the generalizability of findings to the receipt of a full scholarship, and our focus on the impact of Promise eligibility may be quite different than the impact of participation in the program. 
We begin by describing the importance of Promise programs and summarizing the existing research on the impact of these programs in improving postsecondary outcomes. We then discuss the details of eligibility for the New Haven Promise and the benefits of the program, followed by a description of our data and methods for the study. Finally we present the results and provide a discussion of the implications of our findings.

\section{Background}

\subsection{The Importance of Promise Programs}

Promise programs all share two key characteristics: (1) they are place-based, or limited to individuals in a particular region; and (2) they provide some level of financial support towards costs of postsecondary education. Place-based scholarships were introduced at the state level as early as 1991, and at least 13 states have developed state-based scholarship programs since that time (Page \& Scott-Clayton, 2015). City-based scholarships have been a more recent phenomenon, with Kalamazoo, Michigan introducing a program in 2005 that provided full tuition to Michigan postsecondary education institutions for Kalamazoo Public School graduates who had attended the district since Kindergarten (Miller-Adams, 2009). Since the introduction of the Kalamazoo Promise, city-based programs have expanded rapidly. Promise programs typically aim to improve economic development for a region, and are expected to drive increases in property values, reductions in poverty, increased rates of employment, and reductions in crime. Shifts in the makeup of the population and human capital development are expected to drive this economic development. In addition to state-based and city-based programs, there are a variety of similar scholarship programs offered by foundations that provide similar benefits to a specific group of students (Le, Mariano \& Faxon-Mills, 2016).

As an intermediate outcome to improved economic well-being, Promise programs aim to increase postsecondary enrollment and success. Many students face financial barriers to enrollment and success in college, and financial aid has been found to have positive impacts on students' likelihood of postsecondary success (Destin \& Oyserman, 2009; Deming \& Dynarski, 2010; Fitzgerald, 2006). Promise programs aim to increase rates of college enrollment and completion by reducing the cost burden of higher education to students through scholarship funding. Beyond addressing financial barriers, scholarship requirements and the 
college-going culture within districts that these programs intend to create may also contribute to improved academic achievement in high school and college (Scott-Clayton, 2011). Higher levels of academic achievement in high school and college are associated with a higher likelihood of college completion (Adelman, 2006).

\subsection{Prior Research and Contributions of this Study}

There is a broad literature that examines the impact of scholarship programs on students' postsecondary outcomes, and most of the research employs strong quasi-experimental methods to examine the causal impacts of these programs. Many of these studies focus on state-based merit scholarships. For example, studies of the Tennessee HOPE, Georgia HOPE, and West Virginia PROMISE programs find increased overall enrollment rates and increased enrollment in four-year colleges (Bruce \& Carruthers, 2014; Cornwell, Mustard \& Sridhar, 2006; Dynarski, 2000). Zhang and Ness (2010) find similarly positive impacts on overall enrollment rates in a study of programs across 14 states. Beyond four-year enrollment, some studies examine other aspects of school choice and college success after enrollment. For example, Cohodes and Goodman (2014) find that a Massachusetts program led to an increase in the likelihood of students choosing in-state public colleges. With regard to persistence rates, an experimental study of Nebraska's Buffet Scholarship finds positive impacts on second year enrollment (Angrist et al., 2015; Angrist, Hudson \& Pallais, 2014). A study of the West Virginia PROMISE program did not find any impacts on persistence, but did find positive impacts on GPA and credits earned (Scott-Clayton, 2011). And despite similar persistence rates, Scott-Clayton (2011) found that students participating in the West Virginia PROMISE had higher rates of degree completion within five years due to faster rates of credit completion. A study of the Tennessee HOPE also did not find an impact on persistence (Bruce \& Carruthers, 2014). Sjoquist and Winters (2012) analyze scholarship programs in Arkansas and Georgia and find no significant effects of the programs on postsecondary degree completion.

Evidence on city-based promise programs is just beginning to emerge. In one of the earliest studies of the Kalamazoo Promise, Andrews, DesJardins and Ranchhod (2010) use difference-in-difference analysis and find that the program increased applications to public in-state colleges and colleges that were more 
selective. Other studies use similar methods and find that programs in Kalamazoo, Knoxville, and Pittsburgh lead to increased enrollment in four-year colleges, though the findings on overall enrollment are mixed (Bartik, Hershbein \& Lachowska, 2015; Bozick, Gonzalez \& Engberg, 2015; Carruthers \& Fox, 2015). Bartik, Hershbein and Lachowska (2015) were also able to look at longer-term outcomes of the Kalamazoo Promise and find increased levels of credit attainment and increased rates of degree and certificate completion.

As mentioned previously, there are also a number of foundation-provided scholarships that have a similar structure, intend to achieve similar goals, and often set some geographic requirements on who can benefit the programs. For the sake of brevity we limit our review of the research to programs most similar to the New Haven Promise.

Given the rapid spread of place-based scholarships across the country, it is important to understand whether these programs are generating the intended positive postsecondary outcomes. And while there are a number of studies of state-based scholarship programs, there are fewer on city-based programs, and the findings to date are mixed. This study adds to the literature on program impact by looking at New Haven's city-based program. In addition, promise programs vary widely in eligibility requirements, characteristics of the scholarship benefits, and context in which they are implemented; this variation may drive important differences in outcomes. By studying programs with varying eligibility requirements and benefits, policymakers may be able to identify the program characteristics and contexts that are associated with success.

\section{Details of the New Haven Promise}

The New Haven Promise is funded by Yale University, The Community Foundation for Greater New Haven, Yale-New Haven Hospital and Wells Fargo. The program has three goals: (1) promoting college education as an aspiration for all NHPS students; (2) assisting graduating students from NHPS to pursue education after high school; and (3) enhancing the growth, stability, and economic development of the City of New Haven. The scholarship is the primary mechanism for achieving these goals, providing up to $\$ 40,000$ ( $\$ 10,000$ annually for four years) to cover costs at public colleges in the state of Connecticut. The program also offers free Free Application for Federal Student Aid (FAFSA) completion workshops for high school 
seniors and their parents, and works with local businesses to provide summer internships to college students who receive Promise funds ("Promise scholars").

The program exclusively serves NHPS, a medium-sized urban public school system located in southern Connecticut with 46 schools spread across 20 neighborhoods. In the 2012-13 academic year, about 21,000 students were enrolled, of which 87 percent were Latino or African-American and 80 percent were eligible for free or reduced-price lunch. NHPS has a full choice system, in which non-residents of the city are allowed to attend NHPS schools. A substantial proportion of students who attend NHPS schools do not reside in New Haven because non-residents are able to attend the districts magnet schools; according to 2013 NHPS, 24 percent of graduates in 2013 were not residents of New Haven in 2013.

Promise programs vary widely in the requirements set for scholarship recipients, the specifics of the scholarship benefits, and the additional non-scholarship services provided. The New Haven Promise has a set of eligibility requirements that are strict relative to other city-based Promise programs. To be initially eligible for the New Haven Promise scholarship, students must meet a range of requirements that include:

- Residency in the City of New Haven

- Continuous enrollment at NHPS school (or a City-approved public charter school), at minimum throughout high school

- No expulsions ${ }^{1}$

- 40 hours of community service in high school

- Attendance rates of at least 90 percent in high school

- A cumulative 3.0 grade point average (GPA) in high school

Promise program participants must also meet requirements to maintain the scholarship while in college. In particular, students must maintain a 2.0 GPA in the first year at their higher education institution and a 2.5 GPA in subsequent years.

\footnotetext{
${ }^{1}$ According to NHPS policy, expulsion is defined as "The discontinuation of educational services provided by the New Haven Public Schools for a period of time from 11-180 school days prescribed by the School Board. Students under expulsion are prohibited from attending or participating in any event or activities where the Unified Code of Conduct is in effect."
} 
The scholarship benefit is scaled based on continuous and concurrent number of years a student is enrolled in NHPS schools and resides in the City of New Haven. Students enrolled in NHPS schools and residing in the City of New Haven from Kindergarten are eligible for the full scholarship amount. Students who are only enrolled in NHPS schools and are residents in high school will receive 65 percent of the overall Promise funds, and the percent of funds received increases for each additional year of enrollment prior to high school.

The scholarship can be used at public, in-state colleges and can be applied to defray the costs of tuition only; fees, room and board, books, and other costs are not covered. In addition, the scholarship is a last dollar scholarship, so the student must apply for other funding (e.g., for Pell grants) before the Promise scholarship is applied. The value of the New Haven Promise scholarship was gradually phased in so that students graduating high school in 2014 were the first students eligible to receive 100 percent of the scholarship benefit, As a result, the 2011 graduating cohort was eligible for up to $\$ 2,500$ (25 percent of the scholarship), the 2012 cohort was eligible for up to $\$ 5,000$, and the 2013 cohort was eligible for up to $\$ 7,500$. In addition, eligibility requirements for GPA and attendance only accounted for the years after the introduction of the Promise, so the 2011 graduating cohort was only held accountable for attendance and GPA in their senior year, the 2012 graduating cohort was only held accountable for attendance and GPA in their junior and senior years, and the 2013 graduating cohort was only held accountable for attendance and GPA in their sophomore, junior and senior years. These students were still held accountable for residency and continuous enrollment throughout high school, as well as meeting the community service requirement.

\section{Data and Descriptive Statistics}

\subsection{Data}

This study used administrative data from NHPS from 2004 through 2013, including data on student demographics and high school enrollment, course files with grades and credit equivalents, disciplinary actions, attendance, and graduation information. The data allowed us to examine the high school trajectory of 2008 through 2013 graduates. NHPS receives data on postsecondary outcomes from the NSC's Student Tracker system, which includes semester-level enrollment data for members of graduating classes. NSC matches 
students based on names and birth dates. More than 95 percent of postsecondary institutions in the U.S. now report to the NSC, providing information on enrollment, and in some cases major and graduation.

Table 4.1 describes the data we used to estimate NHPS students' eligibility for the New Haven Promise. We were only able to access data on four of the six eligibility criteria for the purposes of this study: continuous enrollment throughout high school, no expulsions in high school, high school attendance of greater than 90 percent since the introduction of the Promise in 2010, and a high school GPA of 3.0 since 2010. We do not have full information on students' residency nor the number of community service hours accumulated while in high school because the district did not consistently record this data for students prior to 2013. To determine whether students met these eligibility requirements, the New Haven Promise relied on self-reported data rather than district-verified records.

NHPS district data included incidents of expulsion and whether a student graduated. We constructed a measure of continuous enrollment using a combination of annual enrollment snapshots and the total days of eligibility in attendance records. We constructed weighted GPA from semester-level course files with grades, credit totals, and course information that identified honors and AP courses, and developed a dichotomous variable to identify students meeting the 3.0 eligibility threshold. ${ }^{2}$ We constructed attendance rates from attendance files with total days of attendance and total days of eligibility and developed an indicator variable to identify students meeting the 90 percent eligibility threshold. To account for the staggered implementation of eligibility requirements, only data from 2010-11 forward was accounted for in GPA and attendance calculations.

We received NSC data by semester from 2008 through 2014. This allowed us to calculate seamless enrollment and one-year persistence rates for our full sample. We used a snapshot date of October $1^{\text {st }}$ of each fall to track annual enrollment in college; students were considered to be seamless enrollees if they were enrolled in October $1^{\text {st }}$ of the year immediately after high school graduation. We identified seamless enrollees who were also enrolled on October $1^{\text {st }}$ of the second year after graduation as persisting. We merged NSC data with data from the Integrated Postsecondary Education Data System (IPEDS), allowing us to identify the

\footnotetext{
${ }^{2}$ While GPAs are regularly calculated within the district, they are not kept on record for accountability purposes.
} 
state where the institution was located, the funding source (public/private non-profit/private for-profit), and the level of the institution (two-year, four-year).

\section{Table 4.1. Data on Eligibility Criteria}

\begin{tabular}{|c|c|c|c|}
\hline Eligibility Criteria & $\begin{array}{l}\text { Years of } \\
\text { Availability }\end{array}$ & Source of Data & Data and Measure Details \\
\hline Residency & 2013-2014 & $\begin{array}{l}\text { NHPS residency } \\
\text { file }\end{array}$ & $\begin{array}{l}2 \text { years of available data insufficient to identify continuous } \\
\text { residency throughout high school; no measure calculated }\end{array}$ \\
\hline $\begin{array}{l}\text { Continuous } \\
\text { enrollment }\end{array}$ & 2004-2014 & $\begin{array}{l}\text { NHPS } \\
\text { enrollment file, } \\
\text { attendance file }\end{array}$ & $\begin{array}{l}\text { annual enrollment file includes annual snapshots; annual } \\
\text { attendance data includes total eligible/ enrolled days; } \\
\text { measure indicates present in all snapshots and eligible for } \\
\text { maximum days each year in high school }\end{array}$ \\
\hline Expulsion* & 2004-2014 & $\begin{array}{l}\text { NHPS discipline } \\
\text { file }\end{array}$ & $\begin{array}{l}\text { annual file indudes all disciplinary actions within an } \\
\text { academic year induding date and type; measure indicates no } \\
\text { expulsions }\end{array}$ \\
\hline Attendance & 2004-2014 & $\begin{array}{l}\text { NHPS } \\
\text { attendance file }\end{array}$ & $\begin{array}{l}\text { annual file indicates total days of attendance and total days } \\
\text { of eligibility/ enrollment; measure indicates total days of } \\
\text { attendance divided by total days of eligibility in a year }\end{array}$ \\
\hline Grade point average & 2008-2014 & $\begin{array}{l}\text { NHPS course } \\
\text { file }\end{array}$ & $\begin{array}{l}\text { annual file indudes data for all courses attempted by } \\
\text { semester; measure incorporates course credits, student } \\
\text { grade, and course level (regular, honors, AP) }\end{array}$ \\
\hline Community service & \multicolumn{2}{|c|}{ not available } & no data; no measure calculated \\
\hline
\end{tabular}

*Incidents of expulsion resulted in fewer than the maximum total days of enrollment in an academic year, so the continuous enrollment and expulsion criteria were duplicative. Moving forward we assume that the expulsion criteria is accounted for by continuous enrollment.

\subsection{Descriptive Statistics}

As shown in Table 4.2, approximately 30 percent of NHPS graduates in each cohort examined were eligible for the Promise according to the GPA, attendance, discipline, and continuous enrollment requirements, with some variation from cohort-to-cohort. Some of this variation may have been due to changing patterns in student outcomes, and some of the variation may have been driven by the incremental roll-out of eligibility requirements. Columns 2 through 4 list the percentage of students who would have been eligible across the full sample (pre- and post-Promise) based on the varying eligibility requirements for each of our three sample cohorts. The actual eligibility rates signify the proportion of students actually eligible for the Promise in each year; no students were eligible prior to the introduction of the Promise in 2010. The hypothetical eligibility rates signify the proportion of students who would have been eligible if the Promise were in place prior to 2010 and the criteria for other cohorts were applicable to those graduates. 
Table 4.2. Percent of Students Eligible for the Promise According to Each Cohort's Requirements

\begin{tabular}{lcccc}
\hline & $\begin{array}{c}\text { Actual } \\
\text { Eligibility } \\
\text { Rates }\end{array}$ & \multicolumn{3}{c}{ Hypothetical Eligibility Rates } \\
& $\begin{array}{c}2013 \\
\text { Requirements }\end{array}$ & $\begin{array}{c}2012 \\
\text { Requirements }\end{array}$ & $\begin{array}{c}2011 \\
\text { Requirements }\end{array}$ \\
\hline 2008 graduates & 0.00 & 0.29 & 0.35 & 0.23 \\
2009 graduates & 0.00 & 0.29 & 0.28 & 0.24 \\
2010 graduates & 0.00 & 0.28 & 0.28 & 0.28 \\
2011 graduates & 0.32 & 0.27 & 0.29 & 0.32 \\
2012 graduates & 0.30 & 0.31 & 0.30 & 0.28 \\
2013 graduates & 0.31 & 0.31 & 0.29 & 0.28 \\
\hline
\end{tabular}

Note: Hypothetical eligibility rates signify the proportion of a cohort's graduates that would qualify for the Promise under the criteria set in each year of the Promise roll-in. Eligibility rates vary by 2011-2013 requirements because the GPA and attendance criteria consider only performance since the introduction of the Promise in 2010-11 (so 2013 requirements look at 3 years of high school data, 2012 requirements look at 2 years of data, etc.).

Table 4.3 presents summary statistics for the 2011 through 2013 cohorts by Promise eligibility status. To narrow in on the population for which regression discontinuity estimates are most relevant, we also present summary statistics for students in the GPA range immediately below and above the eligibility cut point. The summary statistics indicate that among all NHPS high school graduates, Promise-eligible students are more likely to be female, more likely to be White or Asian (and less likely to be Black or Hispanic), and less likely to participate in the free- or reduced-price lunch, Special Education ${ }^{3}$, or English Language Learner (ELL) program than NHPS high school graduates who did not meet the Promise eligibility requirements. We also find that Promise-eligible and non-eligible students in our sample have different postsecondary outcomes on average. Promise-eligible students are more likely to be enrolled in college (of all types) and more likely to persist once enrolled.

\footnotetext{
${ }^{3}$ Note that the special education designation does not include gifted children.
} 
Table 4.3. Summary Statistics by Promise Eligibility and Cohort

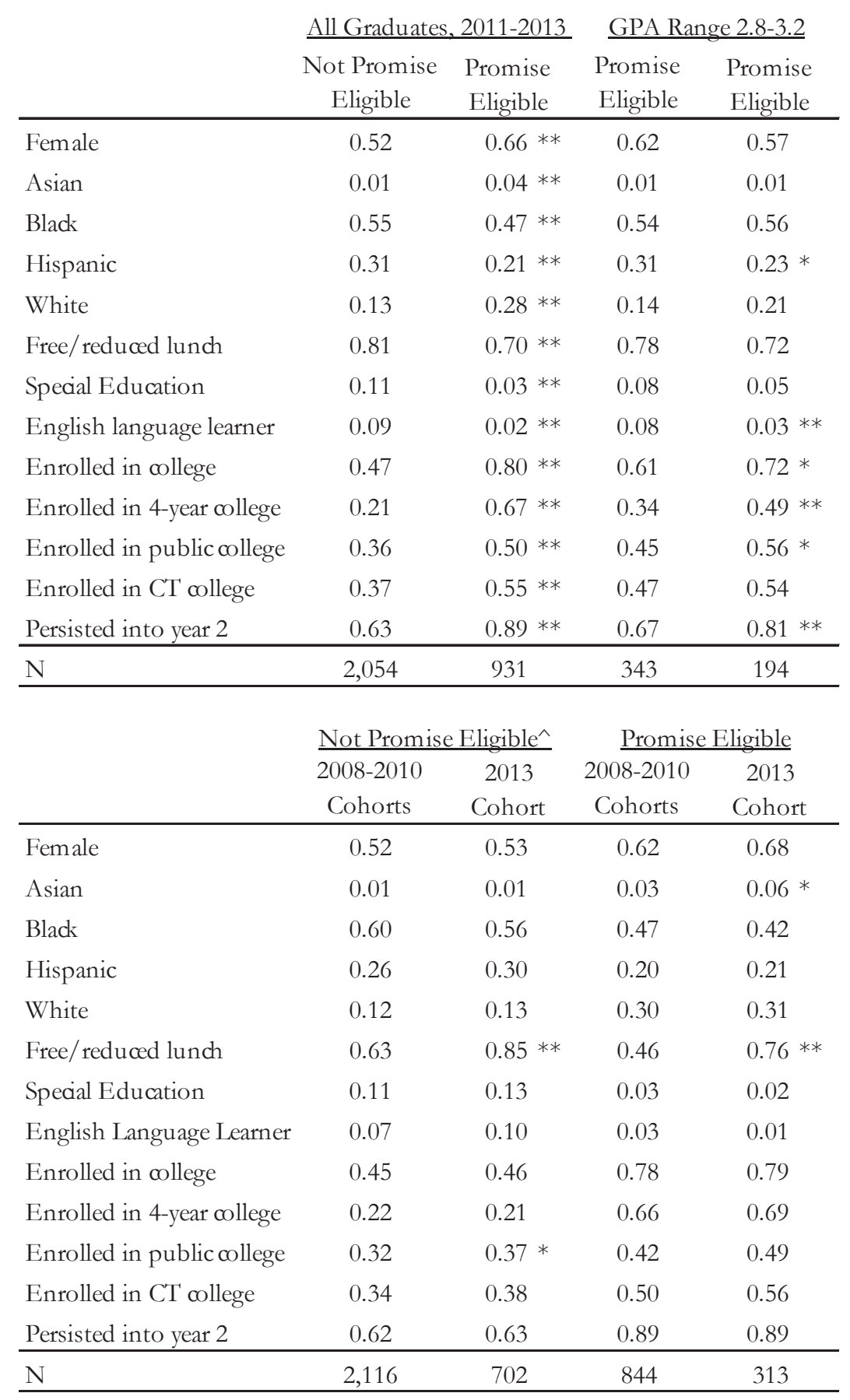

Note: $*$ represents stastically significant differences at the $\mathrm{p}<0.05$ level, $* *$ represents statistically significant differences at the $\mathrm{p}<0.01$ level. ${ }^{\wedge}$ The summary statistics for 2011 and 2012 cohorts are similar to those for 2013; we chose to limit to a single post-Promise cohort to reflect the data used for the difference-in-difference analyses which are run separately for post-Promise cohorts. 
For the purposes of the difference-in-difference analysis, we also present summary statistics for NHPS high school students who graduated immediately prior to the introduction of the Promise in 2010 (prePromise cohorts graduating 2008-2010) compared to those who graduated after the inception of the Promise (post-Promise cohorts graduating 2011-2013); we did this for Promise-eligible and non-eligible graduates. ${ }^{4}$

There are few statistically significant differences in demographics between the pre-Promise and postPromise cohorts for eligible and non-eligible students. The main exception is participation in the free- or reduced-price lunch program; the percentage of students eligible participating in the program was significantly higher in the post-Promise period for both eligible and non-eligible groups. In addition, among students who met eligibility requirements, the percentage Asian doubled between the pre- and post-Promise periods, while there was no difference for non-eligible students. Postsecondary outcomes were also similar for students in pre- and post-Promise periods. While enrollment and persistence rates appear to be slightly high for the 2013 cohort, these differences were largely non-significant, with the exception of public college enrollment rates for students who did not meet eligibility requirements.

\section{Methods}

\subsection{Research Design}

It is first important to describe our reasons for focusing on eligibility for the Promise rather than actual receipt of Promise funds. The first reason for our focus on eligibility is that Promise programs may have impacts on eligible students even if they do not actually apply for and receive the scholarship funds. An example of this is the case of the student who decides to attend college because of the availability of Promise but actually ends up enrolling in a private college where Promise funds cannot be used. In addition, the students who apply for the scholarship are a select group of students who may be different from other students in the district across unobservables such as increased motivation to attend college and ability to follow through with applications. While our methods, particularly regression discontinuity, are designed to account for many of the unobservable differences between eligible and ineligible students, we cannot use our

\footnotetext{
${ }^{4}$ Given that eligibility requirements vary by year due to the incremental roll-out of the program, we present statistics for the 2013 cohort only in the post-Promise period, and the comparable students in the 2008-2010 cohorts.
} 
methods to account for unobservable differences between eligible students who apply for the Promise and eligible students who don't apply for the Promise. As a result, we would be concerned bias in any estimates that focus on application for/receipt of Promise funds as the treatment.

As documented in Table 4.3, students who are eligible for the Promise are different from non-eligible students along student characteristics that are associated with postsecondary outcomes. We therefore must account for these differences in our analytic model. Regression discontinuity design accounts for many of these differences by mimicking random assignment to Promise eligibility. This approach compares students with GPAs that fell right below the eligibility cutoff to students who just met the eligibility cutoff under the assumption that when controlling for observable characteristics, students scoring just below 3.0 are likely to be relatively similar to students scoring just above 3.0 across unobservable characteristics. In addition, we control for observable characteristics to lower the standard errors of the estimates and improve power.

Our regression discontinuity approach employs the following model:

$$
Y_{i}=\text { OMET_GPA } A_{i}+f\left(G P A_{i}\right)+\text { ATTEND }_{i} \mu+\text { ENROLL }_{i} \alpha+X_{i} \beta+e_{i}
$$

Where $Y_{i}$ are our various postsecondary outcomes, $G_{P A}$ is the student's GPA, MET_GPA $A_{i}$ is an indicator variable equal to 1 if a student has a Promise-eligible GPA of 3.0 or higher, ATTEND ${ }_{i}$ and ENROLL $L_{i}$ are other measures of eligibility, $\mathrm{X}_{\mathrm{i}}$ is a vector of observable covariates, and $\mathrm{e}_{\mathrm{i}}$ is a random disturbance term. The function $f(\cdot)$ is function of GPA that captures the relationship between the outcome and GPA away from the program eligibility cutoff. The covariates we include in the model are gender, race/ethnicity, eligibility for the free- or reduced-price lunch program, designation as an ELL, and participation in the Special Education program. We also include fixed effects for year and high school from which a student graduated.

We test several different specifications of our regression discontinuity model. Best practices in regression continuity suggest that models should be limited to an optimal bandwidth, so our primary models limit the analysis to the optimal bandwidth, half the optimal bandwidth, and double the optimal bandwidth. ${ }^{5}$

\footnotetext{
${ }^{5}$ There are several approaches to choosing this optimal bandwidth (Calonico, Cattaneo, \& Titiunik, 2014; Imbens \& Kalyanaraman, 2012; Imbins \& Lemieux, 2008). The optimal bandwidths for this paper are generated through the Imbens \& Kalyanaraman, 2012 approach.
} 
For the optimal bandwidth model we run both linear and quadratic specifications. Finally, while our primary models control for other eligibility requirements, we also run models that limit the analysis to students who met the 90 percent attendance requirement and the continuous enrollment requirement (in separate models).

The key assumption underlying regression discontinuity is that falling just above or below the 3.0 GPA cutoff is not systematically related to other factors related to postsecondary outcomes that are outside of the controls in the model. If students are able to manipulate their GPAs to get above the eligibility threshold, there is a threat to the research design. This assumption can be tested by examining the distribution of GPA and baseline covariates and examining whether they indicate a discontinuity at the 3.0 GPA cutoff (Imbens and Lemieux, 2008). As we will describe below, our tests of the key regression discontinuity assumption indicate mixed results. So we supplement our primary analytic method with an alternative method.

As a robustness check against our regression discontinuity approach, we use a difference-indifference model. Our difference-in-difference model compares eligible and non-eligible students in the prePromise and post-Promise periods. We hypothesize that if the Promise scholarship has a positive impact on college enrollment, then we would expect to see postsecondary outcomes increase more for eligible students than for non-eligible students. We use the following model:

$$
\mathrm{Y}_{\mathrm{i}}=\text { OPROMISE } \mathrm{P}_{\mathrm{i}}+\text { MET_CRITERIA } \mathrm{j} \mu+\text { POST_PROMISE } \mathrm{i} \alpha+\mathrm{X}_{\mathrm{i}} \beta+\mathrm{e}_{\mathrm{i}}
$$

Where $Y_{i}$ represents our various postsecondary outcomes, MET_CRITERIA $A_{i}$ is an indicator variable equal to 1 if a student met the attendance, continuous enrollment and GPA criteria (regardless of graduation year), POST_PROMISE $\mathrm{i}_{\mathrm{i}}$ is an indicator variable equal to 1 if a student graduated after the introduction of the program in 2010, PROMISE $\mathrm{i}_{\mathrm{i}}$ is an indicator variable equal to 1 if a student graduated after the Promise was introduced and met eligibility criteria (i.e., was eligible for the Promise, MET_CRITERIA ${ }_{\mathrm{i}}{ }^{*}$ POST_PROMISE $\mathrm{i}_{\mathrm{i}}$, $\mathrm{X}_{\mathrm{i}}$ is a vector of observable covariates, and $\mathrm{e}_{\mathrm{i}}$ is a random disturbance term. The observable characteristics we account for include gender, race/ethnicity, eligibility for 
the free- or reduced-price lunch program, designation as an ELL, and participation in the Special Education program. In addition, we include fixed effects for year of graduation and school.

Given the incremental roll-out of eligibility criteria, our MET_CRITERIA variable will be different depending on the cohort being examined (e.g. for the 2011 graduating cohort, only senior GPA was used vs junior and senior GPA for the 2012 graduating cohort). We therefore run separate models for each Promiseeligible cohort based on the varying standards from 2011 to 2013. In each model we exclude the other postPromise cohorts that were not subject to the same eligibility standards (i.e., in the model estimating effects for the 2011 cohort, we've excluded data from the 2012 and 2013 graduating cohorts).

\subsection{Interpretation}

Our approaches were designed to produce internally valid estimates of the effect of being eligible for the New Haven Promise. Students who are eligible for the Promise must submit an application to qualify for the program and receive the scholarship, so we are examining the effect of eligibility for the program rather than the effect of receiving the scholarship. In addition, changes in postsecondary enrollment could operate through changes in the likelihood of applying to a particular university, the probability of acceptance conditional on application, or the probability of enrollment conditional on acceptance, and we cannot determine which of these mechanisms are generating enrollment effects.

There are a few things to note about the regression discontinuity analysis in particular. First, the estimates of our regression discontinuity model are "local" to the cutoff. If the effects of eligibility on postsecondary outcomes differ for students whose GPAs are right at the 3.0 cut point relative to students with higher GPAs, our estimates might not represent the average effects for all eligible students. In addition, we may be concerned about other cut points that may be important for college enrollment that fall at a 3.0 GPA, in which case we might interpret the estimates as joint impacts of the Promise and other programs or policies with a 3.0 cut point. For example, if many colleges require a 3.0 GPA for admission, our estimates are capturing both the impact of qualifying for admission at additional colleges and the impact of Promise eligibility. 
Second, data limitations around eligibility hinder our ability to estimate the effect of the New Haven Promise. Because we cannot measure residency and community service, we may be misclassifying students as eligible for the Promise when in fact they are ineligible. Residency is a particular concern; analysis of the 2013 data indicates that only 76 percent of all 2013 graduates were residents of the City of New Haven, and among students we deemed eligible according to other Promise requirements, nearly one-third were non-residents. To the degree that we are misclassifying students as eligible, our estimates will be downwardly biased, meaning that the true effect of eligibility for the New Haven Promise is likely to have been somewhat higher than our actual estimates.

Third, the impact of the Promise on early cohorts of students may not be representative of the full effect of the program given the incremental roll-out of scholarship benefits and eligibility requirements. While the amount of the scholarship for graduates in the 2014 cohort and beyond was up to $\$ 10,000$ per year, the maximum scholarship amounts for graduates in our sample ranged from $\$ 2,500$ to $\$ 7,500$. In addition, we were not able to account for variation in the size of benefits due to the amount of tuition owed, other financial aid received, and varying benefit levels according to residency and enrollment prior to high school. The minimum benefit a student in our sample might be eligible for annually is $\$ 1,625$ (for a 2011 graduate enrolled in NHPS only for high school), and the actual amount received might be lower if college costs fall below this level and/or financial aid from other sources result in lower costs than the maximum allowable scholarship.

\section{Results}

\subsection{Tests of the Regression Discontinuity Identification Assumptions}

As described above, the regression discontinuity assumptions can be tested by determining whether students immediately below the 3.0 GPA cutoff differ from students immediately above the 3.0 GPA cutoff across key covariates of interest. Table 6.1 presents the estimates of discontinuities in the baseline covariates. There appear to be no discontinuities at the GPA cut point for gender, race/ethnicity, and ELL status. 
However, students falling just at or above 3.0 are six percent less likely to participate in the Special Education program relative to those who fall immediately below. ${ }^{6}$

\section{Table 6.1. Discontinuity Estimates for Key Covariates}

\begin{tabular}{lc}
\hline Female & 0.050 \\
& $(0.031)$ \\
Asian & -0.007 \\
& $(0.008)$ \\
Black & 0.017 \\
& $(0.032)$ \\
Hispanic & 0.014 \\
& $(0.029)$ \\
White & -0.025 \\
& $(0.024)$ \\
Free/reduced lunch & -0.047 \\
& $(0.027)$ \\
Special education & $-0.060 * *$ \\
& $(0.016)$ \\
English language learner & 0.004 \\
& $(0.016)$ \\
\hline
\end{tabular}

Note: Values in parentheses are standard errors. * represents stastically significant differences at the $\mathrm{p}<0.05$ level, $* *$ represents statistically significant differences at the $\mathrm{p}<0.01$ level

A second test of the identification assumption is to examine whether the distribution of GPA is continuous at the cut point (McCrary, 2008). If the distribution of GPA is discontinuous at the 3.0 cut point, this might be evidence of possible selection bias due to students sorting by GPA by characteristics that may be related to postsecondary outcomes. The jump in the distribution at the 3.0 GPA cut point in Figure 6.1 suggests that students may be manipulating their GPAs to meet eligibility requirements, and these students may differ in substantive ways from students who fall below the cut point. The McCrary test statistic confirms that there is a significant discontinuity at the 3.0 cut point, with a point estimate of 0.66 and a standard error of 0.09 . This raises concerns that students above the cut point are substantively different from

${ }^{6}$ As a robustness check we run the primary model excluding Special Education students and find no substantive differences in results. 
students below the cut point along unobservable characteristics (e.g. motivation) that are not accounted for in our analysis; in this case regression discontinuity estimates may overestimate the effect of the Promise.

\section{Figure 6.1. Distribution of Eligible GPA}

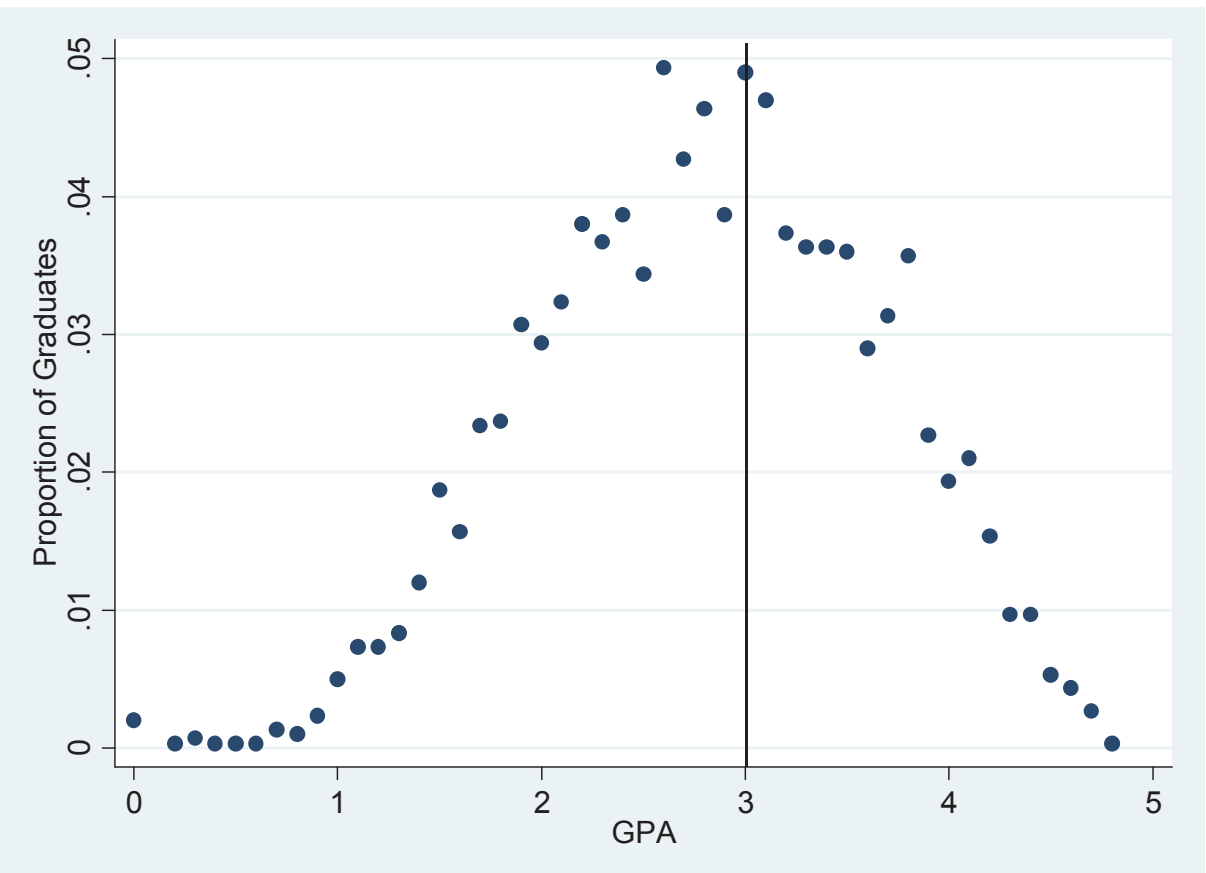

\subsection{Regression Discontinuity Results}

Before examining the regression discontinuity estimates of the New Haven Promise from the regression discontinuity analysis, it is useful to examine the graphical results. Figures 6.2 through 6.6 present scatter plots for each of our postsecondary measures. Figure 6.4 on enrollment at a public college is the only plot that indicates a clear discontinuity at the 3.0 cut point.

Table 6.2 presents the estimates of being eligible for the New Haven Promise program. We present six models, including models I through III which assume a linear specification and adopt varying bandwidths, model IV which assumes a quadratic specification and the optimal bandwidth, and models V and VI which limit the analysis to students who meet other eligibility requirements (attendance and continuous enrollment, respectively) and assume a linear specification. 
Figure 6.2. Enrollment at Any College

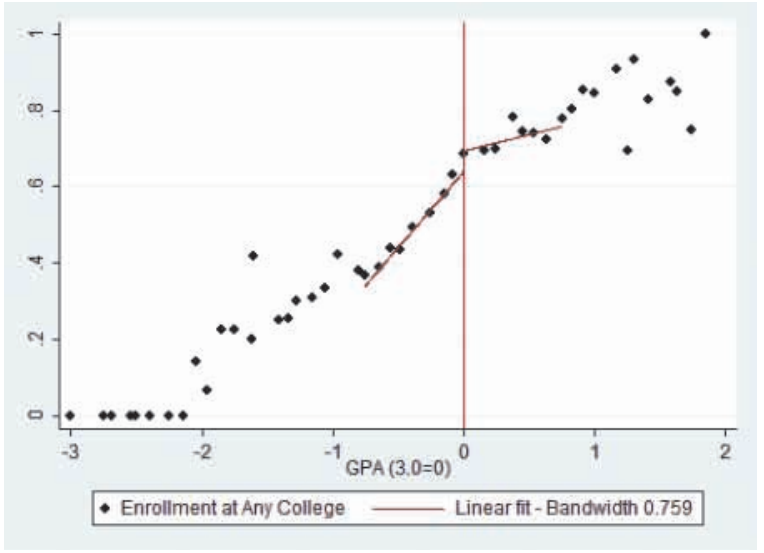

Figure 6.3 Enrollment at a Public College

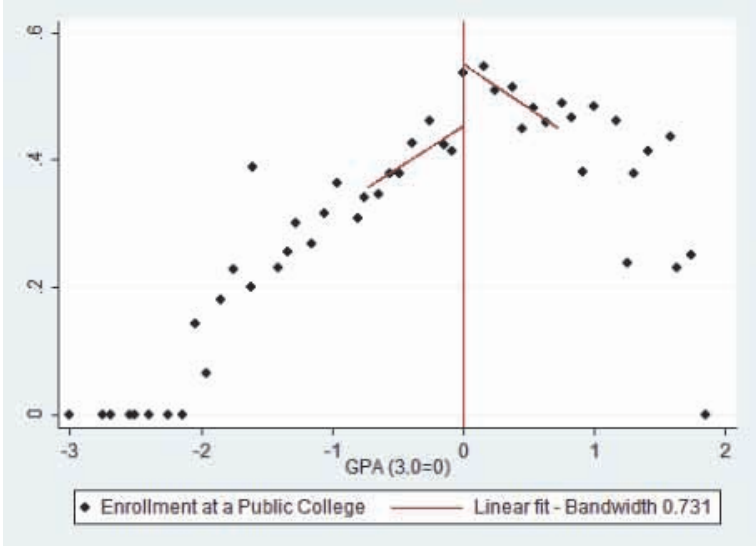

Figure 6.4. Enrollment at a Four-Year College Figure 6.5 Enrollment at a Connecticut College
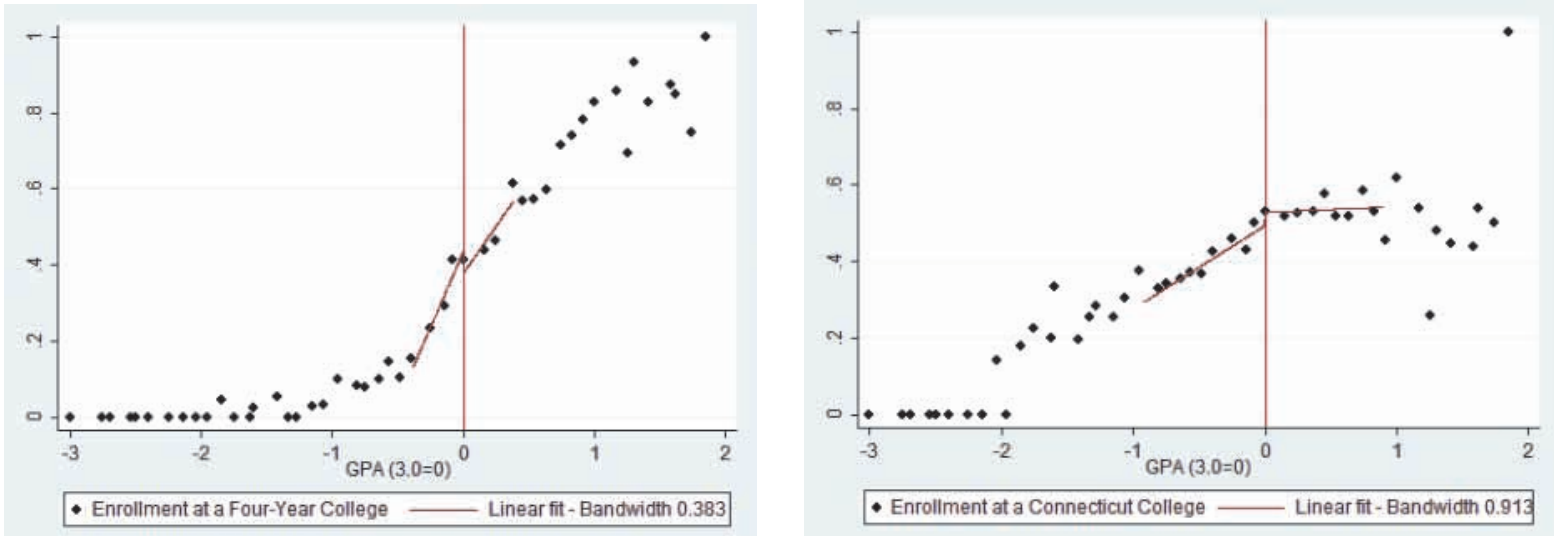

Figure 6.6. Persistence into $2^{\text {nd }}$ Fall of Enrollment

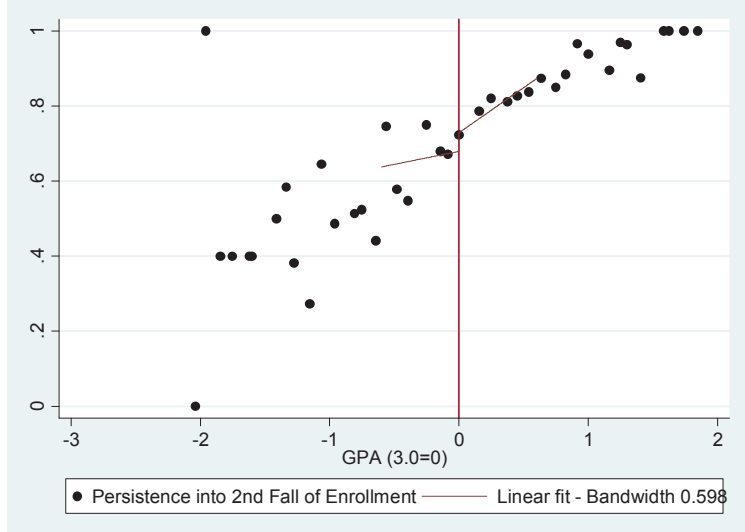

The most prominent result is the presence of a positive, statistically significant impact on public college enrollment across most of the models, with the estimated impacts ranging an 8 to 14 percentage point 
increase in enrollment at a public college among graduates who qualify for the Promise. The results for enrollment at any college, enrollment in a four-year college, and enrollment in a Connecticut college are mixed. Several of the models indicate positive, statistically significant estimates, but the estimates vary widely in size, direction and significance, so we cannot conclude that there is a positive impact of the Promise on these outcomes. Results for persistence are not significant across any of the models, indicating that we cannot conclude the New Haven Promise had an impact on these outcomes. However, it is interesting to note that the point estimates for persistence are consistently positive and meaningful in size, so we suspect that future analyses with additional cohorts of data might find positive statistically significant impacts on persistence as standard errors become smaller.

Table 6.2. Regression Discontinuity Estimates of the Impact of the New Haven Promise Program

\begin{tabular}{lcccccc}
\hline & $\mathrm{I}$ & $\mathrm{II}$ & $\mathrm{III}$ & $\mathrm{IV}$ & $\mathrm{V}$ & $\mathrm{VI}$ \\
\hline Enrolled in any college & 0.037 & 0.019 & $\mathbf{0 . 0 6 9} *$ & 0.013 & 0.051 & $\mathbf{0 . 0 8 4} *$ \\
& $(0.042)$ & $(0.060)$ & $(0.032)$ & $(0.063)$ & $(0.035)$ & $(0.033)$ \\
Enrolled in public college & 0.084 & $\mathbf{0 . 1 3 6} *$ & $\mathbf{0 . 0 8 8} *$ & $\mathbf{0 . 1 4 4} *$ & 0.063 & $\mathbf{0 . 0 8 1} *$ \\
& $(0.046)$ & $(0.065)$ & $(0.034)$ & $(0.068)$ & $(0.037)$ & $(0.035)$ \\
Enrolled in four-year college & -0.079 & -0.040 & 0.005 & -0.030 & $\mathbf{0 . 1 0 6} * *$ & $\mathbf{0 . 1 4 1} * *$ \\
& $(0.058)$ & $(0.085)$ & $(0.041)$ & $(0.087)$ & $(0.035)$ & $(0.033)$ \\
Enrolled in CT college & 0.019 & 0.002 & $\mathbf{0 . 0 6 5 *}$ & -0.001 & 0.024 & 0.044 \\
& $(0.041)$ & $(0.058)$ & $(0.032)$ & $(0.061)$ & $(0.038)$ & $(0.035)$ \\
Persisted into 2nd fall of & 0.073 & 0.093 & 0.041 & 0.053 & 0.060 & 0.047 \\
enrollment & $(0.058)$ & $(0.083)$ & $(0.042)$ & $(0.089)$ & $(0.043)$ & $(0.041)$ \\
\hline GPA bandwidth limited & $\mathrm{X}$ & $\mathrm{X}$ & $\mathrm{X}$ & $\mathrm{X}$ & & $\mathrm{X}$ \\
Quadratic GPA relationship & & & & & $\mathrm{X}$ & $\mathrm{X}$ \\
Met other eligibility criteria & & & & & & \\
\hline
\end{tabular}

Note: Values in parentheses are standard errors. ${ }^{*}$ represents stastically significant differences at the $\mathrm{p}<0.05$ level, ** represents statistically significant differences at the $\mathrm{p}<0.01$ level. Optimal bandwidths by outcome are as follows: any college (0.759), public college (0.731), four-year college (0.383), CT college (0.913), persistence (0.598). Models I-III assume a linear specification and use the optimal bandwidth (I), half the optimal bandwidth (II), and twice the optimal bandwidth. Model IV assumes the optimal bandwidth and a quadratic specification. Models V and VI use all data and assume a linear specification but limit the analysis to students who met other criteria, including attendance $(\mathrm{V})$ and continuous enrollment (VI). 


\subsection{Difference-in-Difference Results}

In Figure 6.7, it does not appear that trends in enrollment rates for eligible graduates after the introduction of the Promise differed markedly from trends for non-eligible graduates. Between 2010 and 2011 enrollment rates for eligible students increased by 3.3 percentage points, but enrollment rates for noneligible students also increased by 2.8 percentage points.

Figure 6.7. Enrollment Rate by Year and Eligibility Status

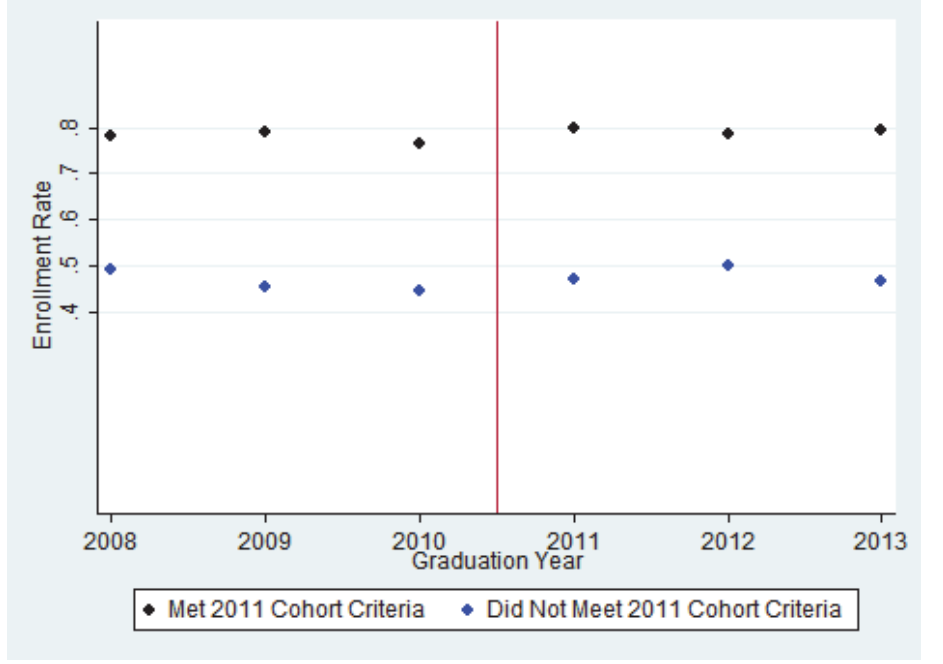

The difference-in-difference estimates for the three cohorts and their varying eligibility requirements in Table 6.3 indicate no evidence of an impact of the Promise on enrollment or persistence. The estimates are substantially smaller than those found in our regression discontinuity analysis, and in some cases the signs of the coefficients became negative. Patterns in the coefficients over time vary by measure, indicating no systematic evolution in the impact of the Promise.

\section{Discussion}

Reducing the costs of college and providing incentives for students to aspire for and succeed in postsecondary education can provide students from struggling cities improved economic opportunities. The prior literature indicates that scholarship programs can increase postsecondary achievement among a wide range of students, and city-based Promise programs are one specific type of scholarship program that have been widely replicated in recent years. The impacts of these programs are therefore important to understand. 
Table 6.3. Difference-in-Difference Estimates of the Impact of the New Haven Promise Program

\begin{tabular}{lccc}
\hline & 2011 Criteria & 2012 Criteria & 2013 Criteria \\
\hline Enrolled in any college & 0.015 & -0.024 & -0.002 \\
& $(0.036)$ & $(0.035)$ & $(0.036)$ \\
Enrolled in four-year & 0.022 & 0.028 & 0.012 \\
& $(0.036)$ & $(0.035)$ & $(0.035)$ \\
Enrolled in public college & 0.019 & 0.042 & 0.023 \\
Enrolled in CT college & $(0.042)$ & $(0.041)$ & $(0.040)$ \\
& 0.018 & -0.027 & 0.040 \\
Persisted & $(0.042)$ & $(0.041)$ & $(0.040)$ \\
& 0.027 & -0.008 & -0.028 \\
& $(0.041)$ & $(0.038)$ & $(0.041)$ \\
\hline
\end{tabular}

Note: Values in parentheses are standard errors. ${ }^{*}$ represents statistically significant differences at the $\mathrm{p}<0.05$ level, $* *$ represents statistically significant differences at the $\mathrm{p}<0.01$ level

Based on the mixed results in this paper, we cannot conclude that eligibility for the New Haven Promise had a significant impact on the postsecondary outcomes of students in the early years of the program's inception. While our primary regression discontinuity model provides some evidence of a potential effect on enrollment a public institution and several other enrollment outcomes, our results are highly sensitive to specifications, and our tests of the key regression discontinuity assumptions raise some concerns about the manipulation of student GPA around the cut point. In addition, our difference-in-difference analysis suggests no impact of the program. The results add to other literature on Promise programs, some of which find positive impacts on postsecondary outcomes, while other studies find mixed effects (Bartik, Hershbein \& Lachowska, 2015; Bozick, Gonzalez \& Engberg, 2015; Carruthers \& Fox, 2015).

We have concerns about the ability of our analysis to estimate the true impact of the New Haven Promise for several reasons. First, the incremental roll-out of the Promise resulted in lower levels of benefits for students in the initial cohorts we examined, so we might expect the postsecondary effects to be smaller for these students relative to the impact for students who are eligible for the full scholarship. In addition, the study looks at the impact of eligibility for the Promise rather than actual participation in the Promise. Rough calculations indicate that in 2013 fewer than 25 percent of students who we identified as eligible for the New Haven Promise submitted an application to participate in the program in these initial cohorts, so the impact 
associated with eligibility for the Promise may be substantially lower than the impact of participation in the Promise. ${ }^{7}$

Second, we faced substantial data challenges that limited our ability to precisely identify the students eligible for the program. We are particularly concerned about the inability to determine residency status for students. Estimates based on data for the 2013 cohort (for which we did have residency data in 2012-13) suggest that nearly a third of students we deem eligible for the Promise may not have truly been eligible, and we would expect this to downwardly bias our results. ${ }^{8}$ We were also missing data on community service and it is unclear how many students failed to be eligible for the New Haven Promise based on this criterion. In addition to missing variables on key criteria, our construction of GPA from course data over time was challenging given limited information on the formulas and rules for calculation, and there is likely measurement error in this key variable of interest. This measurement error would also downwardly bias results, and could be a particular challenge for our regression discontinuity strategy, as it relies on the GPA requirement specifically and requires precise calculation of this measure. On the other hand, the fact that other college-related requirements may also rely on a 3.0 cut point suggests that we might also be concerned about upward bias in our estimates because they may conflate Promise impacts with impacts of other programs and policies.

If we assume that the lack of evidence for a Promise effect represents a true lack of impact of the program, it is useful to consider why this may be the case when other studies of regional Promise programs have demonstrated positive impacts on postsecondary outcomes. One possibility is the strictness and complexity of eligibility requirements; the New Haven Promise has among the strictest and most complex requirements of Promise programs we are aware of. Some other programs like the Kalamazoo Promise and the El Dorado Promise focus explicitly on residency and enrollment requirements and do not set requirements for academic achievement, attendance, or community service. More complex eligibility

\footnotetext{
${ }^{7}$ For the purposes of these calculations we used residency data for 2013 to more precisely identify the number of truly eligible students in the 2013 graduating cohort, so we identify 208 students as eligible (without residency, this number would have been 313). Community service data remains missing.

${ }^{8}$ We did have residence data for one year, 2013, so we were able to test for the implications of including this for our 2013 cohort. We found that at least for this cohort, the inclusion of single-year residency did not change our findings substantively.
} 
requirements may create uncertainty because students may not understand the criteria and may not be certain they can actually meet these criteria, and this uncertainty reduces the expected value of the program to the student. Yet these added requirements can also provide benefits to students; programs that set standards for GPA, attendance and community service can help students to better prepare for and succeed in college. Our identification strategies rely on the assumption that students are not able to manipulate their eligibility status, so we cannot directly measure these benefits in our analysis.

The high level of the GPA requirement in particular may limit the ability to generate a strong impact on college enrollment. Table 4.3 indicates that Promise-eligible graduates from NHPS have an 80 percent college attendance rate, which is relatively high compared to the rates of pre-program enrollment rates of graduates in districts with less restrictive eligibility requirements. For example, Bartik, Hershbein \& Lachowska (2015) find that pre-program enrollment rates were just 60 percent among eligible students in Kalamazoo prior to the introduction of their promise program. Other programs that set GPA requirements of 2.0 or 2.5 as well as programs without GPA requirements have a larger pool of potential non-enrollees on which to generate impacts.

It may also be that the early years of the New Haven Promise do not provide a complete picture of the program's impacts when fully implemented. While the study was not designed to evaluate implementation, we hypothesize that several factors may contribute to this. Given the gradual phase-in of benefits, none of the cohorts in our sample were eligible to receive the full $\$ 10,000$ annual scholarship. In addition, any difficulties we describe above regarding the ability of students to understand the program and its complex eligibility requirements may have been particularly challenging in the early years. And even among students who understood the program, the limited time frame in which to shift college aspirations and prepare for college may have limited the ability of students to successfully enroll and persist. Analysis of data for graduating cohorts from 2014 on can shed light on whether the program effects become stronger as the program is fully implemented and better understood by students and their families. 


\section{References}

Adelman, C. (2006). The Toolbox Revisited: Paths to Degree Completion From High School Through

College. US Department of Education.

Andrews, R.J., DesJardins, S.L. and Ranchhod, V. (2010). The effects of the Kalamazoo Promise on college choice. Economics of Education Review, 29(5), 722-737.

Angrist, J., Autor, D., Hudson, S., and Pallais, A. (2015). Evaluating econometric evaluations of postsecondary aid. American Economic Review, 105(5), 502-07.

Angrist, J., Hudson, S., and Pallais, A. (2014). Leveling Up: Early Results from a Randomized Evaluation of PostSecondary Aid. National Bureau of Economic Research Working Paper No. 20800.

Bartik, T.J., Hershbein, B. and Lachowska, M. (2015). The Effects of the Kalamazoo Promise Scholarship on College Enrollment, Persistence, and Completion. Upjohn Institute Working Paper 15-229. Kalamazoo, MI: W.E. Upjohn Institute for Employment Research.

Bozick, R., Gonzalez, G., and Engberg, J. (2015). Using a Merit-Based Scholarship Program to Increase Rates of College Enrollment in an Urban School District: The Case of the Pittsburgh Promise. Journal of Student Financial Aid, 45(2), 2.

Bruce, D. J. and Carruthers, C. K., (2014). Jackpot? The impact of lottery scholarships on enrollment in Tennessee. Journal of Urban Economics, 81, 30-44.

Calonico, S., Cattaneo, M.D., and Titiunik, R. (2014) Robust Nonparametric Confidence Intervals for Regression Discontinuity Designs. Econometrica, 82(6), 2295-2326.

Carruthers, C. K. and Fox, W. F. (2015). Aid for all: College coaching, financial aid, and post-secondary persistence in Tennessee. University of Tennessee, Haslam College of Business, Working Paper 2015-06.

Cohodes, S. R. and Goodman, J. S. (2014). Merit aid, college quality, and college completion: Massachusetts' Adams scholarship as an in-kind subsidy. American Economic Journal: Applied Economics, 6 (4), 251-285.

Cornwell, C., Mustard, D. and Sridhar, D. (2006). The enrollment effects of merit-based financial aid: 
Evidence from Georgia's HOPE Scholarship. Journal of Labor Economics 24: 761-86.

Deming, D. and Dynarski, S.M.. (2010). “College Aid.” In Targeting Investments in Children: Fighting Poverty When Resources Are Limited, Phillip B. Levine and David J. Zimmerman, eds. Chicago: National Bureau of Economic Research and University of Chicago Press, 283-302.

Destin, M. and Oyserman, D. (2009). From Assets to School Outcomes: How Finances Shape Children's Perceived Possibilities and Intentions. Psychological Science 20(4), 414-418.

Dynarski, S. M. (2000). Hope for whom? Financial aid for the middle class and its impact on college attendance. National Tax Journal, 53 (3): 629-61.

Fitzgerald, B.K. (2006). “Lowering Barriers to College Access: Opportunities for More Effective Coordination of State and Federal Student Aid Policies.” In P. C. Gándara, G. Orfield, and C. L. Horn (Eds.), Expanding opportunity in higher education: Leveraging promise. Albany, NY: State University of New York Press.

Gonzalez, G.C., Bozick, R., Daugherty, L., Scherer, E., Singh, R., Suarez, M., Ryan, S. and Schweig, J. (2014). New Haven Promise: An Early Look at College Preparation, Access, and Enrollment of New Haven Public School Students (2010-2013). Santa Monica: RAND Corporation, RB-9811.

Imbens, G. and Kalyanaraman, K. (2012). Optimal bandwidth choice for the regression discontinuity estimator. Review of Economic Studies, 79(3), 933-959.

Imbens, G. and Lemieux, T. (2008). Regression discontinuity designs: A guide to practice. Journal of Econometrics, 142(2), 615-635.

Le, V., Mariano, L.T., and Faxon-Mills, S. (2016). Can College Outreach Programs Improve College Readiness? The Case of the College Bound, St. Louis Program. Research in Higher Education, 57(3), 261-287.

McCrary, J. (2008) "Manipulation of the running variable in the regression discontinuity design: A density test." Journal of Econometrics, 142(2), 698-714. .

Miller-Adams, M. (2009). The power of a promise: Education and economic renewal in Kalamazoo. Kalamazoo, MI: W.E. Upjohn Institute for Employment Research. 
Page, L.C. and Scott-Clayton, J. (2015). Improving College Access in the United States: Barriers and Policy Responses. National Bureau of Economic Research Working Paper No. 21871.

Scott-Clayton, J. (2011). On money and motivation: A quasi-experimental analysis of financial incentives for college achievement. Journal of Human Resources, 46(3): 614-46.

Sjoquist, D. L. and Winters, J. V. (2012). Building the stock of college educated labor revisited. Journal of Human Resources, 47(1), 270-285.

Zhang, L. and Ness, E. C. (2010). Does state merit-based aid stem brain drain? Educational Evaluation and Policy Analysis, 32(2), 143-165. 